\title{
Topotecan and small interfering RNA suppress survivin expression synergistically in Caki-1 renal cancer cells: Direct suppression of survivin and enhancement of transfection efficiency by topotecan
}

\author{
AKINORI SATO, KEIICHI ITO, TAKAKO ASANO, MAKOTO SUMITOMO, \\ TOMOHIKO ASANO and MASAMICHI HAYAKAWA \\ Department of Urology, National Defense Medical College, 3-2 Namiki, Tokorozawa, Saitama 359-8513, Japan
}

Received June 28, 2007; Accepted August 29, 2007

\begin{abstract}
Survivin is an apoptosis inhibitor found in many tumors but not in most normal differentiated tissues, which makes it an exciting target for cancer therapy. Survivin expression has been shown to be associated with cell proliferation in renal cancer and we previously demonstrated the possibility of treating renal cancer with survivin-specific siRNA and topotecan, which increased the uptake of siRNA by KU19-20 renal cancer cells. We found in the present study that the combination of siRNA and topotecan inhibits survivin expression in Caki-1 renal cancer cells by another mechanism. Caki-1 renal cancer cells expressed higher level of survivin than KU19-20 cells did and survivin-specific siRNA alone suppressed survivin expression only slightly. The combination of topotecan and siRNA suppressed survivin expression completely and inhibited cell proliferation. Topotecan itself did not increase cellular uptake of siRNA but suppressed survivin expression. It also increased transfection efficiency without increasing cellular uptake of siRNA. Although the mechanism of action varies between cell lines, combination therapy using topotecan and siRNA should offer an attractive approach for treatment of advanced renal cancer.
\end{abstract}

\section{Introduction}

Renal cell carcinoma (RCC) accounts for $2-3 \%$ of adult cancers and for $2 \%$ of cancer-related deaths (1), and the prognosis for patients with advanced RCC is extremely poor. The 5-year survival rate for patients with metastatic RCC is only about 5\% (2). Conventional systemic chemotherapy and radiotherapy are usually ineffective (3) and only 10-20\% of the patients respond to treatment with interferons (IFNs)

Correspondence to: Dr Akinori Sato, Department of Urology, National Defense Medical College, 3-2 Namiki, Tokorozawa, Saitama 359-8513, Japan

E-mail: zenpaku@ndmc.ac.jp

Key words: renal cancer, survivin, siRNA, topotecan, transfection efficiency
(4). Many combination therapies have been proposed in efforts to improve the treatment efficacy, but their response rates are also insufficient: $11-43 \%$ for the combination of IFN- $\alpha$ and vinblastine, $0-29 \%$ for the combination of IFN- $\alpha$ and interleukin-2, and $0-47 \%$ for the combination of IFN- $\alpha$, interleukin-2, and 5-fluorouracil (5). Recently, tyrosine kinase inhibitors were shown to prolong progression-free survival, but their effect was not curative (6).

Abnormalities in the control of apoptosis play an important role in tumorigenesis, and one of the inhibitors of apoptosis is survivin (7), which is expressed in the $G_{2} / M$ phase of the cell cycle and associates with the microtubules in the mitotic spindle. When overexpressed, survivin has oncogenic potential because it can overcome the $\mathrm{G}_{2} / \mathrm{M}$ checkpoint to ensure mitotic progression (8). It also inhibits the terminal effector proteases caspase-3 and caspase-7 (9). Because survivin is found in many tumors but is not found in most normal differentiated tissues (10), inhibiting its action is an exciting topic in cancer therapy.

We have already shown in the KU19-20 RCC cell line that the expression of survivin is associated with cell proliferation and that the combination of the topoisomerase I inhibitor topotecan and survivin-specific small interfering RNA (siRNA) synergistically inhibits survivin expression and cell proliferation $(11,12)$. Suppressing the expression of survivin might thus be an effective way to treat advanced RCC.

The suppression of survivin expression by siRNA is a promising approach to selective cancer therapy $(12,13)$, but the transfection efficiency of liposome-mediated gene delivery is generally low and differs between cell types. Our previous result showed that survivin-specific siRNA suppressed the expression of survivin in KU19-20 cells effectively when its cellular uptake was increased by using it in combination with topotecan (12).

Our study here shows that the RCC cell line Caki-1 expresses a higher level of survivin than the KU19-20 line and that treatment with survivin-specific siRNA alone suppresses survivin expression only slightly even though the siRNA is successfully taken up into the cell. Combined treatment with siRNA and topotecan did not increase cellular uptake of siRNA but did suppress survivin expression completely and inhibited cell proliferation. Interestingly, 
unlike in KU19-20 cells, we found that topotecan itself inhibited survivin expression in Caki-1 cells. We also found that topotecan increases transfection efficiency without increasing the cellular uptake of siRNA.

\section{Materials and methods}

Cell culture. The Caki-1 RCC cell line was obtained from the American Type Culture Collection (Rockville, MD, USA). Cells were grown in DMEM medium containing $10 \%$ fetal bovine serum and $0.3 \%$ penicillin-streptomycin (Invitrogen, Carlsbad, CA, USA).

Treatment with survivin-specific siRNA and topotecan. One day before treatment, cells were plated in 6-well (for Western blot analysis and cell cycle analysis) or 96-well (for cell proliferation assay) culture plates. The survivin-specific siRNA or non-sense siRNA (Santa Cruz Biotechnology, Santa Cruz, CA) was mixed with Lipofectamin 2000 reagent (Invitrogen) according to the manufacturer's instruction. Then the mixture was administered to the cells in the DMEM medium containing topotecan (Calbiochem, San Diego, CA, USA) at concentrations ranging from 0 to $0.1 \mu \mathrm{g} / \mathrm{ml}$. The concentration of siRNA was set at $100 \mathrm{nM}$. For simultaneous treatment, cells were maintained in this medium for $48 \mathrm{~h}$ and then assayed for survivin expression and cell proliferation. For metachronous treatment, cells were first maintained for $24 \mathrm{~h}$ in DMEM medium containing survivin-specific siRNA but not topotecan, maintained for another $24 \mathrm{~h}$ in DMEM containing topotecan $(0-1 \mu \mathrm{g} / \mathrm{ml})$ and then assayed for survivin expression and cell proliferation.

Cell proliferation assay. Cells were plated in 96-well culture plates one day before treatment and then incubated under the indicated conditions for $48 \mathrm{~h}$, after which cell proliferation was determined using the MTT assay.

Cell cycle analysis. After treatment under the indicated conditions, cells were washed with PBS and harvested by trypsinization. They were then resuspended in citrate buffer, stained with propidium iodide following the method by Vindelov et al (14), and then analyzed by flow cytometry using the CellQuest program for calculation of the different cell cycle phases.

Measurement of cellular uptake of siRNA. Cells were transfected with fluorescein-labeled non-sense siRNA (Santa Cruz Biotechnology) by the method described above and cultured in the DMEM medium with or without topotecan $(0-0.1 \mu \mathrm{g} / \mathrm{ml})$ for $48 \mathrm{~h}$. They were then washed with PBS and harvested by trypsinization, after which the cellular uptake of fluorescein-labeled siRNA was measured by flow cytometry using the CellQuest program.

Western blot analysis. Cells were homogenized for $15 \mathrm{~min}$ on ice in RIPA buffer ( $50 \mathrm{mM}$ Tris, $150 \mathrm{mM} \mathrm{NaCl}, 1 \mathrm{mM}$ EDTA, $1 \mathrm{mM}$ PMSF, $0.25 \%$ sodium deoxycholate, $1 \mathrm{mM}$ $\mathrm{Na}_{3} \mathrm{VO}_{4}, 1 \mathrm{mM} \mathrm{NaF}, 1 \% \mathrm{NP} 40$ and protease-inhibitor mixture). Protein concentrations were measured using the DC Protein Assay Reagent (Bio-Rad Laboratories, Hercules,

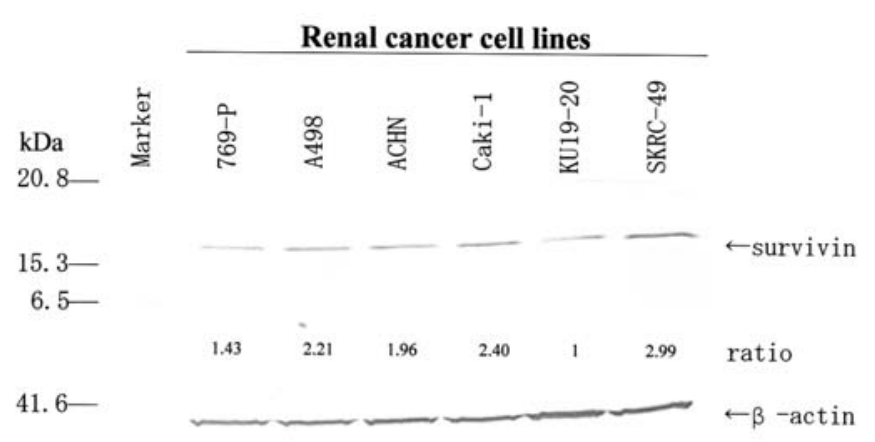

27. $7-$

Figure 1. Expression of survivin in renal cancer cell lines. Survivin Western blot analysis. Caki-1 cells expressed a 2.4-fold higher level of survivin than did KU19-20 cells. Ratio = (survivin level) $/($ survivin level for the KU19-20 line). Both levels were normalized by the corresponding level of $\beta$-actin expression.

CA, USA). Samples were mixed with loading buffer, resolved by $12.5 \%$ SDS-PAGE and transferred onto nitrocellulose membranes. After blocking with 5\% dry skimmilk, the membranes were incubated for either $1 \mathrm{~h}$ or overnight with anti-survivin rabbit polyclonal antibody (Alpha Diagnostic International, San Antonio, TX, USA). Then the membranes were incubated at room temperature first for $1 \mathrm{~h}$ with a biotinylated secondary goat anti-rabbit antibody (BioRad Laboratories) and then for another hour with streptavidin-biotinylated alkaline phosphatase complex (Bio-Rad Laboratories). Immunoreactivity was detected using an alkaline phosphatase substrate kit following the manufacturer's protocol (Bio-Rad Laboratories). The level of survivin expression was semiquantified using the public domain NIH Image program and normalized to the level of $\beta$-actin expression.

\section{Results}

Transfection efficiency differs between cell types, even between the various types of RCC cells, making it difficult to use RNA interference for general treatment of cancer. We therefore combined the survivin-specific siRNA with topotecan because we had found in the KU19-20 line of RCC cells that topotecan increases transfection efficiency by increasing the uptake of siRNA (12). The level of survivin expressed by Caki- 1 cells was 2.4 times that expressed by KU19-20 cells (Fig. 1). Treatment with only survivinspecific siRNA for $48 \mathrm{~h}$ suppressed survivin expression only slightly, whereas simultaneous treatment with survivinspecific siRNA and topotecan for $48 \mathrm{~h}$ synergistically suppressed survivin expression (Fig. 2A) and inhibited cell proliferation (Fig. 2B and C). Interestingly, topotecan itself inhibited survivin expression in Caki-1 cells in a dosedependent manner. Cell cycle analysis also revealed the increased sub- $G_{1}$ fraction, which included apoptotic cells induced by the suppression of survivin and decreased $\mathrm{G}_{2} / \mathrm{M}$ fraction (Fig. 3).

To investigate whether topotecan increases transfection efficiency in Caki-1 cells by the same mechanism that it does in KU19-20 cells, we evaluated the changes in the cellular 
A
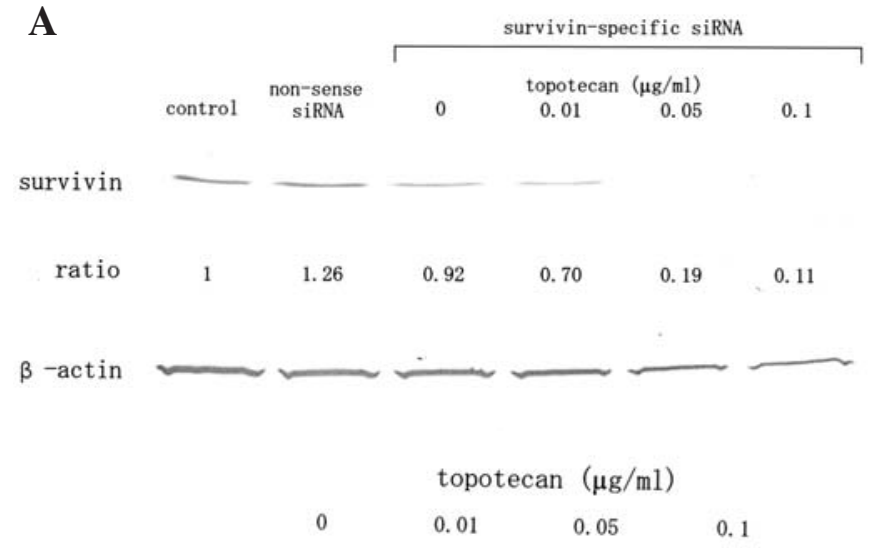

survivin

ratio

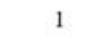

0.89

0.62

0.55

$\beta$-actin

B

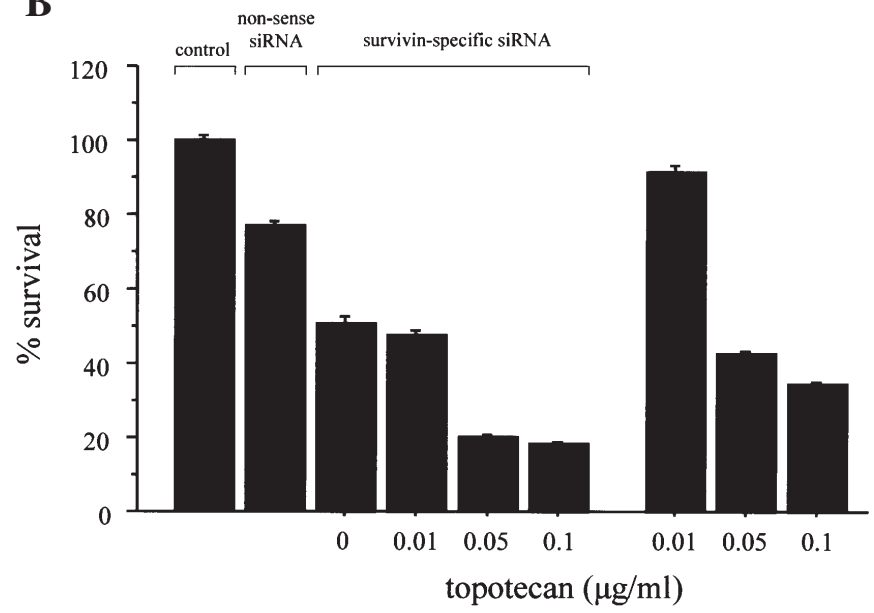

C

siRNA(-)
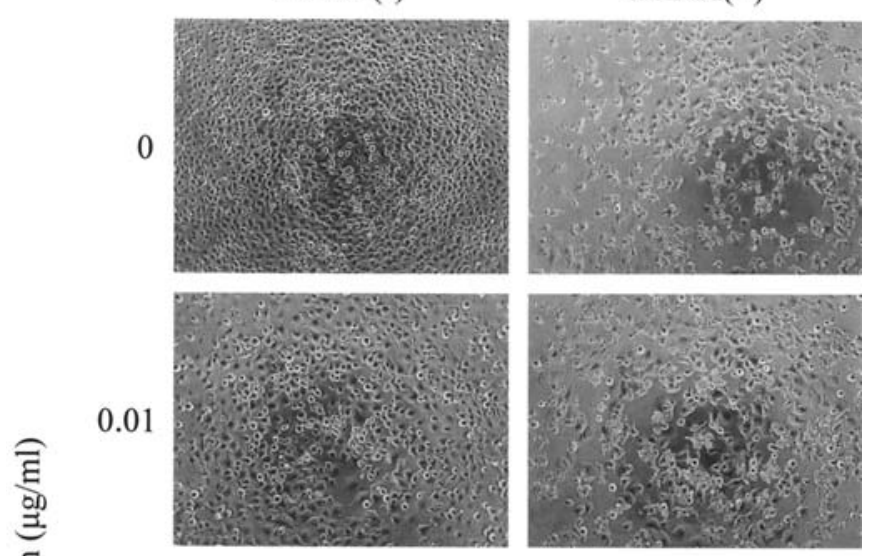

0.05
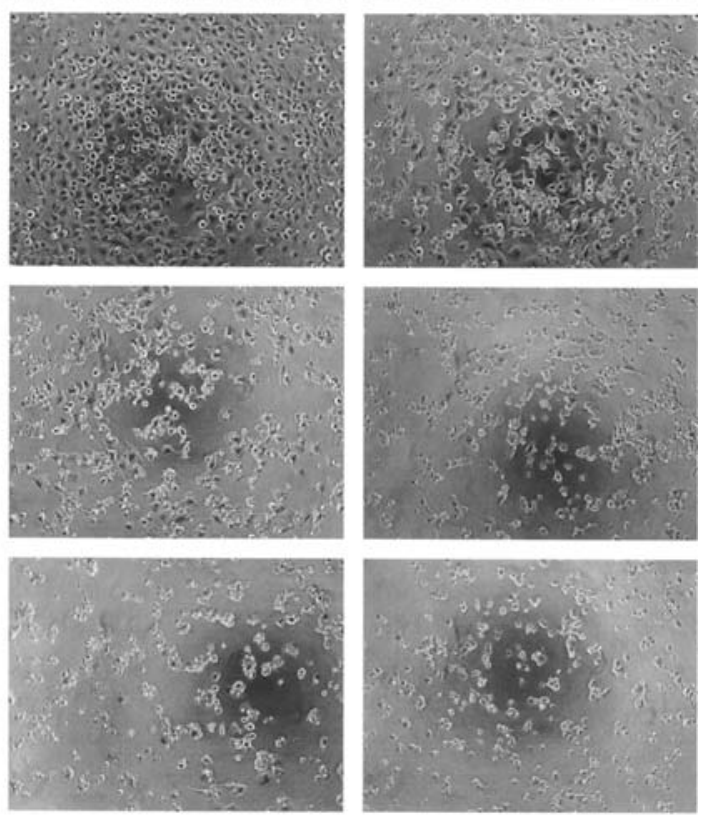

Figure 2. Inhibition of survivin expression and cell proliferation by simultaneous treatment with topotecan and survivin-specific siRNA for 48 h. (A) Survivin Western blot analysis. Survivin expression was synergistically suppressed by the combination of topotecan and siRNA. Note that treatment with siRNA alone suppressed survivin expression only slightly. Topotecan itself also suppressed survivin expression in a dose-dependent manner. Ratio $=($ survivin level $) /($ control survivin level $)$. Both levels were normalized by the corresponding level of B-actin. (B) Cell viability using MTT assay. (C) Microscopic examination. Cell proliferation was further inhibited by the combination of topotecan and siRNA.
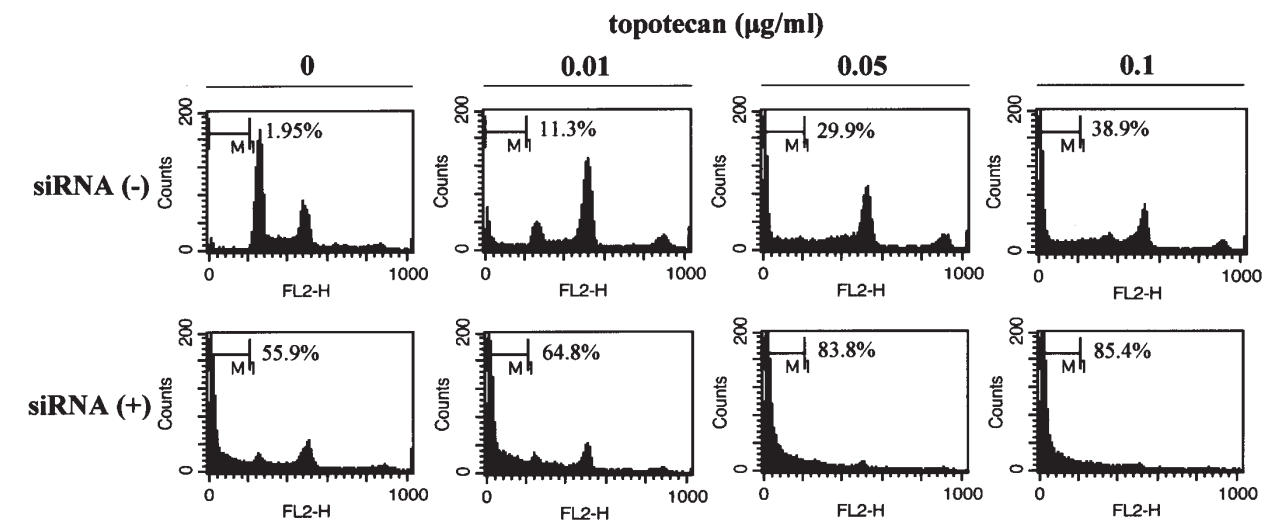

Figure 3. Cell cycle analysis after 48-h treatment with topotecan alone and in combination with survivin-specific siRNA. The combination of topotecan and

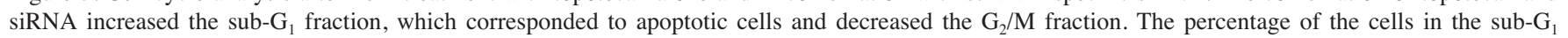
fraction is shown.

uptake of siRNA by using fluorescein-labeled non-sense siRNA. The cellular uptake of siRNA was not affected by the treatment with topotecan for $48 \mathrm{~h}$ (Fig. 4). From these results, we inferred that the effect of the combination of topotecan and siRNA was in part simultaneous suppression of survivin by both of the agents. 

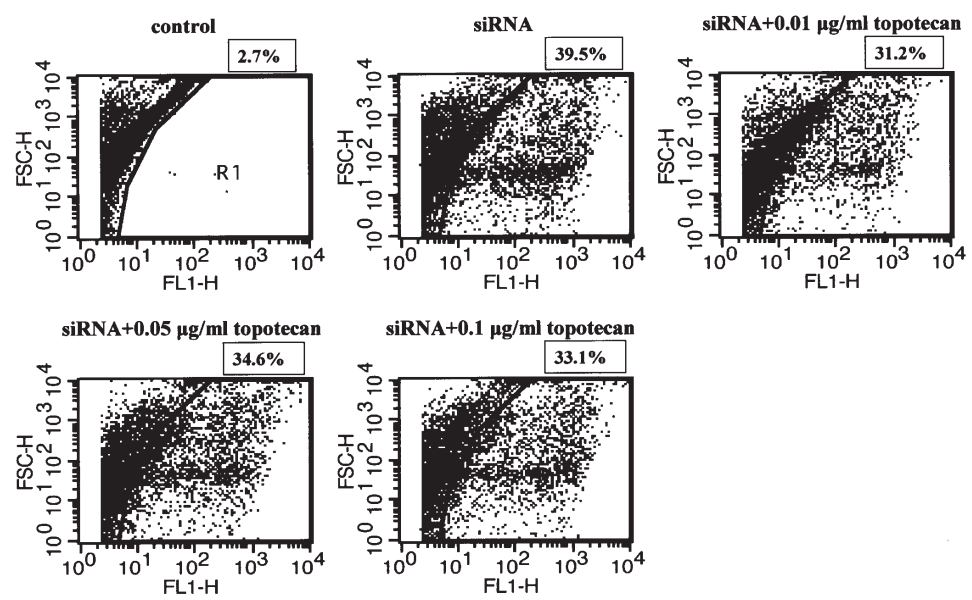

Figure 4. Analysis of cellular uptake of siRNA after 48-h treatment with topotecan and fluorescein-labeled non-sense siRNA by flow cytometry. Percentage of the cells taking up siRNA is shown. Topotecan did not increase cellular uptake of siRNA in Caki-1 cells.

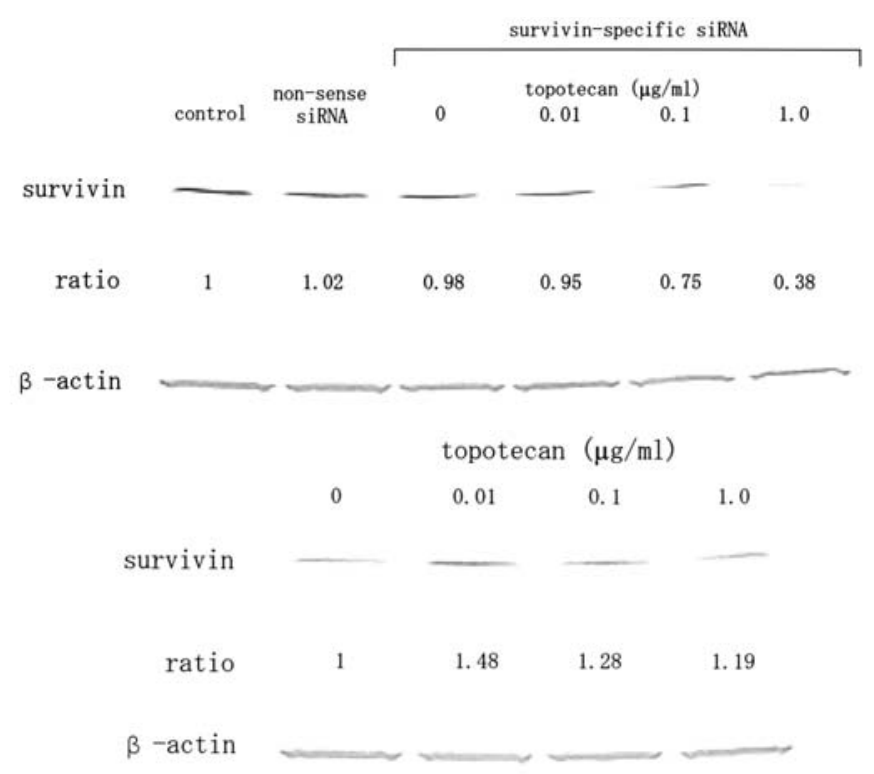

Figure 5. Changes in survivin expression by metachronous treatment with topotecan and survivin-specific siRNA. Survivin Western blot analysis. Survivin expression was inhibited by the metachronous administration of topotecan $24 \mathrm{~h}$ after transfection of siRNA. Note that treatment with siRNA alone suppressed survivin expression only slightly and that topotecan itself did not suppress survivin expression. Ratio $=($ survivin level $) /($ control survivin level). Both levels were normalized by the corresponding level of B-actin.

Their combined effect, however, was synergistic, so one could hypothesize that topotecan increased transfection efficiency not by increasing the cellular uptake but in some other way. When Caki-1 cells were treated first with siRNA for $24 \mathrm{~h}$ and then with topotecan for another $24 \mathrm{~h}$ (metachronous treatment), survivin expression was further inhibited by the addition of topotecan, whereas survivin expression was not suppressed by topotecan itself (Fig. 5). It is noteworthy that the treatment with siRNA suppressed survivin only slightly. The effect of topotecan on cellular uptake of siRNA was negligible because the siRNA was removed before the cells were treated with topotecan. This result supports the hypothesis that topotecan increases the transfection efficiency without increasing cellular uptake.

\section{Discussion}

Expression of survivin is associated with carcinogenesis, tumor progression and decreased survival (15). Survivin is found in many tumors but not in most normal differentiated tissues (10) and has therefore been recognized as an attractive target for cancer therapy. We have previously shown that survivin expression is associated with cell proliferation in RCC cells (11). Considering the low rate with which advanced $\mathrm{RCC}$ responds to various systemic therapies, we have tried to completely suppress survivin expression in Caki-1 cells, which express a high level of survivin and do not respond to survivin-specific siRNA treatment, by combining the use of siRNA and topotecan.

RNA interference has been widely used in tumor gene therapy and the suppression of survivin by siRNA has been shown to decrease the survival of various cancer cells $(13,16-18)$. Complete suppression of survivin expression by liposome-mediated transfection of siRNA, however, is often difficult in part because of the relatively low transfection efficacy of non-viral vectors (19). Many investigators have therefore tried to increase transfection efficiency by combining liposomes with agents such as topoisomerase II inhibitor, steroids and insulin (20-22). In the present study, we combined siRNA with topotecan, which has been shown to increase the cellular uptake of siRNA by KU19-20 RCC cells (12). Topotecan is a topoisomerase I inhibitor widely used in the treatment of various cancers such as small cell lung cancer, ovarian cancer and cervical cancer (23-25). Its effectiveness against renal cancer, however, has been investigated only in one small phase-II study (26).

The use of topotecan in combination with survivinspecific siRNA decreased the expression of survivin and inhibited cell proliferation dramatically. Topotecan did not increase the uptake of siRNA by Caki-1 cells, as it does of siRNA by KU19-20 cells, but did decrease survivin expression in a dose-dependent manner. This discrepancy in cellular uptake might be due to a difference between the cell lines. That is, Caki-1 cells might be more capable of taking up siRNA than KU19-20 cells are. KU19-20 cells were able to take up only small amount of siRNA $(5.3 \%$ 
without topotecan) and therefore cellular uptake could be increased to its maximum level by topotecan (30.8\%) (12), whereas the amount of siRNA taken up by Caki-1 cells might not have been increased by topotecan because the siRNA uptake by Caki-1 cells is already almost at its maximum level $(39.4 \%)$ without topotecan. The effect of topotecan on survivin expression has been discussed in only a few reports. A study on prostate cancer cells stated that topotecan decreased survivin expression (27). Topotecan was recently shown to inhibit cell proliferation by inhibiting the expression of epidermal growth factor receptor (EGFR) (28), and epidermal growth factor (EGF) was reported to increase survivin expression $(16,29)$. Considering the role of EGFR in RCC (30), one might speculate that topotecan suppresses survivin expression by inhibiting EGFR expression and that its effect on survivin expression differs between cell lines depending on the contribution of EGFR signaling to survivin expression.

Another mechanism of the suppression of survivin by the combination therapy might be the change in the cell cycle. Li et al reported that survivin was expressed in the $\mathrm{G}_{2} / \mathrm{M}$ phase and was associated with the microtubules in the mitotic spindle (8). According to the cell cycle analysis in the present study, the number of cells in the $\mathrm{G}_{2} / \mathrm{M}$ fraction was dramatically decreased by the combination of siRNA and topotecan, which may in part explain the further suppression of survivin.

Furthermore, topotecan might have increased the transfection efficiency because the combination of topotecan and siRNA suppressed survivin expression synergistically. The metachronous treatment excluded the influence of topotecan on the cellular uptake of lipoplex and showed that the combination of siRNA and topotecan decreased survivin expression, whereas topotecan itself did not. In this treatment the topotecan itself probably could not suppress survivin expression because the cells were treated with topotecan for only half as long as they were in the simultaneous treatment. This result suggests that topotecan may be able to decrease survivin expression by increasing the transfection efficiency without increasing cellular uptake. The basic mechanism of lipofection is that lipoplexes are brought into cells by endocytosis, trapped in endosomes, released into the cytoplasm and transported to the nucleus (31). Transfection efficiency will therefore be influenced by factors affecting each step, and numerous studies have focused on this issue. Topotecan was shown to increase cellular uptake of liposome in another line of RCC cells (12). Progesterone and cholesterol may increase the intracellular transport to the nucleus, and cholesterol may also have an effect on cellular uptake (21). Topoisomerase II inhibitors increase the random integration of transfected vectors into human chromosomes (20). Tamaddon et al demonstrated that the release of oligodeoxynucleotides from endosomes was dependent on the factors such as $\mathrm{pH}$ and temperature (32), and synthetic influenza-based diINF-7 peptide was recently shown to increase the endosomal escape of complexes and improve the silencing efficiency (33). To our knowledge, there has been no report that topotecan increased transfection efficiency without increasing the cellular uptake of lipoplexes. Topotecan may also increase transfection efficiency by stimulating the intracellular trans- port of liposome and release of siRNA into the cytoplasm from endosomes.

In summary, the combination of topotecan and survivinspecific siRNA completely suppressed survivin expression. Topotecan itself suppressed survivin expression and increased transfection efficiency without increasing the cellular uptake of siRNA. Although the mechanism by which this combination therapy acts may differ between cell lines, this combination therapy could shed light on the development of novel treatment modality for advanced renal cancer.

\section{Acknowledgments}

We thank Professor Wolfgang Schulz (Heinrich-HeineUniversity, Germany) for his critical reading of the manuscript and valuable discussion.

\section{References}

1. Landis SH, Murray T, Bolden S and Wingo PA: Cancer statistics. CA Cancer J Clin 49: 8-31, 1999.

2. Motzer RJ, Bander NH and Nanus DM: Renal-cell carcinoma. N Engl J Med 335: 865-875, 1996.

3. Mulders P, Figlin R, De Kernion JB, Wiltrout R, Linehan M, Parkinson D, de Wolf $\mathrm{W}$ and Belldegrun A: Renal cell carcinoma: recent progress and future directions. Cancer Res 57: 5189-5195, 1997.

4. Pittman K and Selby P: The management of renal cell carcinoma. Crit Rev Oncol Hematol 16: 181-200, 1994.

5. Autenrieth M, Heidenreich A and Gschwend JE: Systemic therapy of metastatic renal cell carcinoma. Urologe A 45: 594-599, 2006.

6. Kane RC, Farrell AT, Saber H, Tang S, Williams G, Jee JM, Liang C, Booth B, Chidambaram N, Morse D, Sridhara R, Garvey P, Justice R and Pazdur R: Sorafenib for the treatment of advanced renal cell carcinoma. Clin Cancer Res 12: 7271-7278, 2006.

7. Altieri DC and Marchisio PC: Survivin apoptosis: an interloper between cell death and cell proliferation in cancer. Lab Invest 79: 1327-1333, 1999.

8. Li F, Ambrosini G, Chu EY, Plescia J, Tognin S, Marchisio PC and Altieri DC: Control of apoptosis and mitotic spindle checkpoint by survivin. Nature 396: 580-584, 1998 .

9. Tamm I, Wang Y, Sausville E, Scudiero DA, Vigna N, Oltersdorf $\mathrm{T}$ and Reed JC: IAP-family protein survivin inhibits caspase activity and apoptosis induced by Fas (CD95), Bax, caspases and anticancer drugs. Cancer Res 58: 5315-5320, 1998.

10. Ambrosini G, Adida C and Altieri DC: A novel anti-apoptosis gene, survivin, expressed in cancer and lymphoma. Nat Med 3: 917-921, 1997.

11. Sato A, Oya M, Ito K, Mizuno R, Horiguchi Y, Umezawa K, Hayakawa M and Murai M: Survivin associates with cell proliferation in renal cancer cells: regulation of survivin expression by insulin-like growth factor- 1 , interferon- $\gamma$ and a novel NF- $\kappa$ B inhibitor. Int J Oncol 28: 841-846, 2006.

12. Sato A, Ito K, Asano T, Sumitomo M, Asano T and Hayakawa M: Synergistic effect of survivin-specific small interfering RNA and topotecan in renal cancer cells: topotecan enhances liposome-mediated transfection by increasing cellular uptake. Int J Oncol 30: 695-700, 2007.

13. Kappler M, Bache M, Bartel F, Kotzsch M, Panian M, Wurl P, Blumke K, Schmidt H, Meye A and Taubert H: Knockdown of survivin expression by small interfering RNA reduces the clonogenic survival of human sarcoma cell lines independently of p53. Cancer Gene Ther 11: 186-193, 2004.

14. Vindelov LL, Christensen IJ and Nissen NI: A detergent-trypsin method for the preparation of nuclei for flow cytometric DNA analysis. Cytometry 3: 323-327, 1983.

15. LaCasse EC, Baird S, Korneluk RG and MacKenzie AE: The inhibitors of apoptosis (IAPs) and their emerging role in cancer. Oncogene 17: 323-327, 1998.

16. Ai Z, Yin L, Zhou X, Zhu Y, Zhu D, Yu Y and Feng Y: Inhibition of survivin reduces cell proliferation and induces apoptosis in human endometrial cancer. Cancer 107: 746-756, 2006. 
17. Paduano F, Villa R, Pennati M, Folini M, Binda M, Daidone MG and Zaffaroni N: Silencing of survivin gene by small interfering RNAs produces supra-additive growth suppression in combination with 17-allylamino-17-demethoxygeldanamycin in human prostate cancer cells. Mol Cancer Ther 5: 179-186, 2006.

18. Ning S, Fuessel S, Kotzsch M, Kraemer K, Kappler M, Schmidt U, Taubert H, Wirth MP and Meye A: siRNA-mediated down-regulation of survivin inhibits bladder cancer cell growth. Int J Oncol 25: 1065-1071, 2004.

19. Li S and Huang L: Non-viral gene therapy: promises and challenges. Gene Ther 7: 31-34, 2000.

20. Fujimaki K, Aratani Y, Fujisawa S, Motomura S, Okubo T and Koyama H: DNA topoisomerase II inhibitors enhance random integration of transfected vectors into human chromosomes. Somat Cell Mol Genet 22: 279-290, 1996.

21. Koster F, Felberbaum R, Finas D, Wunsch K, Schulz C, Diedrich K and Hauser C: Progesterone and estradiol enhance lipid mediated transfection of Sk-Br-3 mammalian cancer cells. Int J Mol Med 9: 617-620, 2002.

22. Ohmiya N, Emi N, Niwa Y, Goto H and Hayakawa T: Insulinenhanced liposome-mediated gene transfer into a gastric carcinoma cell line. Clin Exp Pharmacol Physiol 29: 544-548, 2002.

23. Eckardt JR: Emerging role of weekly topotecan in recurrent small cell lung cancer: Oncologist 9 (Suppl 6): 25-32, 2004

24. McGuire WP, Blessing JA, Bookman MA, Lentz SS and Dunton CJ: Topotecan has substantial antitumor activity as first-line salvage therapy in platinum-sensitive epithelial ovarian carcinoma: a Gynecologic Oncology Group Study. J Clin Oncol 18: 1062-1067, 2000.

25. Moore DH: Chemotherapy for recurrent cervical carcinoma. Curr Opin Oncol 18: 516-519, 2006.
26. Law TM, Ilson DH and Motzer RJ: Phase II trial of topotecan in patients with advanced renal cell carcinoma. Invest New Drugs 12: 143-145, 1994

27. Griffith TS and Kemp TJ: The topoisomerase I inhibitor topotezcan increases the sensitivity of prostate tumor cells to TRAIL/ Apo-2L-induced apoptosis. Cancer Chemother Pharmacol 52: 175-184, 2003.

28. Mialon A, Sankinen M, Soderstrom H, Junttila TT, Holmstrom T, Koivusalo R, Papageorgiou AC, Johnson RS, Hietanen S, Elenius $\mathrm{K}$ and Westermarck J: DNA topoisomerase I is a cofactor for c-Jun in the regulation of epidermal growth factor receptor expression and cancer cell proliferation. Mol Cell Biol 25: 5040-5051, 2005.

29. Qiu L, Wang Q, Di W, Jiang Q, Schefeller E, Derby S, Wanebo H, Yan B and Wan Y: Transient activation of EGFR/ AKT cell survival pathway and expression of survivin contribute to reduced sensitivity of human melanoma cells to betulinic acid. Int J Oncol 27: 823-830, 2005.

30. Schoffski P, Dumez H, Clement P, Hoeben A, Prenen H, Wolter P, Joniau S, Roskams T and Van Poppel H: Emerging role of tyrosine kinase inhibitors in the treatment of advanced renal cell cancer: (Review). Ann Oncol 17: 1185-1196, 2006.

31. Dass CR: Lipoplex-mediated delivery of nucleic acids: factors affecting in vivo transfection. J Mol Med 82: 579-591, 2004.

32. Tamaddon AM, Shirazi FH and Moghimi HR: Modeling cytoplasmic release of encapsulated oligonucleotides from cationic liposomes. Int J Pharm 336: 174-182, 2007.

33. Oliveira S, van Rooy I, Kranenburg O, Storm G and Schiffelers RM: Fusogenic peptides enhance endosomal escape improving siRNA-induced silencing of oncogenes. Int J Pharm 331: 211-214, 2007. 